\title{
EFECTO DE META-TOPOLINA SOBRE LA PROPAGACIÓN in vitro DE Rhodophiala splendens EN MEDIO LÍQUIDO
}

\section{EFFECT OF META-TOPOLINE ON in vitro PROPAGATION OF Rhodophiala splendens IN LIQUID CULTURE MEDIUM}

\author{
Jara, G.', Seemann, P.', Muñoz, M.', Riegel, R.', Schiappacasse, F. ${ }^{2}$, Peñailillo, P. ${ }^{2}$ y Basoalto, A. ${ }^{2}$ \\ 'Instituto de Producción y Sanidad Vegetal, Universidad Austral de Chile, Valdivia, Chile. \\ E-mail: gjara@uach.cl \\ ${ }^{2}$ Departamento de Horticultura, Universidad de Talca, Talca, Chile.
}

\section{INTRODUCCIÓN}

Las citoquininas son un grupo de reguladores de crecimiento involucradas en múltiples funciones en el desarrollo de las plantas, desde la germinación de las semillas hasta la senescencia. Estas se encuentran naturalmente en las plantas o son preparadas sintéticamente, como el N6-benzilaminopurina, 6-furfurylaminopurina, entre otras, siendo en su mayoría del tipo isoprenoides. Sin embargo, existen otro tipo de citoquininas del tipo aromáticas, aisladas de derivados hidroxilados del BAP, conocidos como topolinas, de las cuales la forma meta es la más activa (Mok et al. 2005). La actividad de estas methoxytopolinas ha sido demostrada mediante bioensayos con crecimiento de callos en tabaco, inducción de síntesis de betacianina en cotiledones de Amaranthus, en la actividad antisenescente en cebada y en la formación de clorofila en cotiledones de pepino. El rol de la citoquininas en la micropropagación convencional utilizando medios sólidos, ha sido analizado en varias especies de Rhodophiala, en las cuales se reportan coeficientes de multiplicación muy bajos (Jara et al.; 2004). Algunos autores han reportado que el uso de medios líquidos es un excelente sistema para aumentar los índices de multiplicación, especialmente mediante el uso de la inmersión temporal en medios suplementados con citoquininas. No obstante, recientemente se ha reportado que la aplicación del BAP en el cultivo bajo inmersión temporal de Musa no aumenta los índices de multiplicación como ocurre con otros cultivos, pero que mediante la aplicación de meta-topolina estos índi- ces se elevan notablemente, evitándose además realizar la fase de alargamiento (Escalona et al. 2003). En base a estos antecedentes es que el presente trabajo tiene como objetivo comparar los índices de multiplicación de microbulbillos in vitro de $R$. splendens, utilizando medios de cultivo adicionado con las citoquininas metatopolina y BAP en forma sólida y líquida, de tal forma de definir concentraciones óptimas para inducir la brotación y bulbificación.

\section{MATERIAL Y MÉTODOS}

Se utilizaron microbulbillos de $R$. splendens originados de semillas, a los cuales se les eliminaron las hojas, raíces y escamas oxidadas para de esta forma realizarles un corte basal y sembrarlos en frascos con $50 \mathrm{~mL}$ de medio de cultivo MS en estado sólido y líquido, adicionado con $0,2,2,4,4$ y $6,6 \mu \mathrm{molL}^{-1}$ de la citoquininas N6-Benzilaminopurina (BAP) y N6- (3-hydroxibenzil) adenina (meta-topolina), de tal forma de completar siete tratamiento en medio sólido y siete tratamientos en medio líquido, con ocho repeticiones por tratamiento y un microbulbillo por frasco. Los cultivos se mantuvieron en cámara de luz artificial con un flujo de fotones fotosinteticamente activos de $50 \mu \mathrm{molm}^{-2} \mathrm{~s}^{-1}$, fotoperiodo de 16 horas luz y una temperatura de $24^{\circ} \mathrm{C}$, evaluándose al cabo de 60 días, la tasa de multiplicación, mediante la relación número de microbulbillos inicial + número microbulbillos final/ número microbulbillos inicial, diámetro ecuatorial y peso fresco de la planta completa, obteniendo de esta forma el incremento de materia fresca de las plántulas. El procesamiento 
estadístico de los datos consistió en el análisis de varianza (ANOVA) y test de Fisher (LSD) sobre el efecto de los factores principales.

\section{RESULTADOS Y DISCUSIÓN}

Del mismo modo como lo reportado para otras especies, la utilización de medios líquidos fue más favorable para aumentar la tasa de multiplicación de R. splendens, la cual presentó un promedio de 2,6 microbulbillos en el medio testigo líquido, en cambio en medios sólidos fue de 1,9. La incorporación de citoquininas al medio de cultivo aumentó la tasa de multiplicación, observándose una mejor respuesta de la metatopolina que del BAP, tanto en medios sólidos como líquidos, con una tasa de multiplicación promedio de 3,4 microbulbillos, sin embargo, esta respuesta no fue significativa, al igual que el estado del medio. Al analizar la interacción para las variables de calidad, solamente el peso de los microbulbillos se encuentra influenciado significativamente por los diferentes tratamientos, con los mayores valores para el medio sólido adicionado con meta-topolina en concentraciones de 2,2-6,6 $\mu \mathrm{mol} \mathrm{L}^{-1}$. En cuanto al calibre de los microbulbillos estos presentaron un rango entre 0,19 y $0,37 \mathrm{~cm}$. A pesar de que solamente se presentaron diferencias estadísticamente significativas para el peso de los microbulbillos, el comportamiento de las demás variables para algunos tratamientos fue más favorable en los medios adicionados con la citoquinina metatopolina en medios líquidos.

\section{BIBLIOGRAFÍA}

ESCALONA, M.; CEJAS, I.; GONZÁLEZ-OLMEDO, J.; CAPOTE, I.; ROELS, S.; CAÑAL, M.J.; RODRÍGUEZ, R.; SANDOVAL, J.; DEBERGH, P. 2003. Efecto de meta-topolina sobre la propagación del plátano utilizando un biorreactor de inmersión temporal. InfoMusa 12:28-30.

JARA, G; SEEMANN, P; MUÑOZ, M.; RIEGEL, R.; SCHIAPACASSE, R; PEÑAILILLO, P.; VICO, V. 2004. Investigaciones preliminares realizadas en torno al establecimiento in vitro de especies chilenas de Rhodophiala. XIV Congreso Científico. INCA. Cuba.

MOK, M.; MARTIN, R.; DOBREV, I.; VANKOVÁ, R. SHING HO, P.; YONEKURA-SAKAKIBARA, K.; SAKAKIBARA, H.; MOK. D. 2005. Topolins and hydroxylated thidiazuron derivates are substrates of cytokinines O-glucosyltransferase with position specificity related to receptor recognition. Plant Physiology 137: 1057-1066.
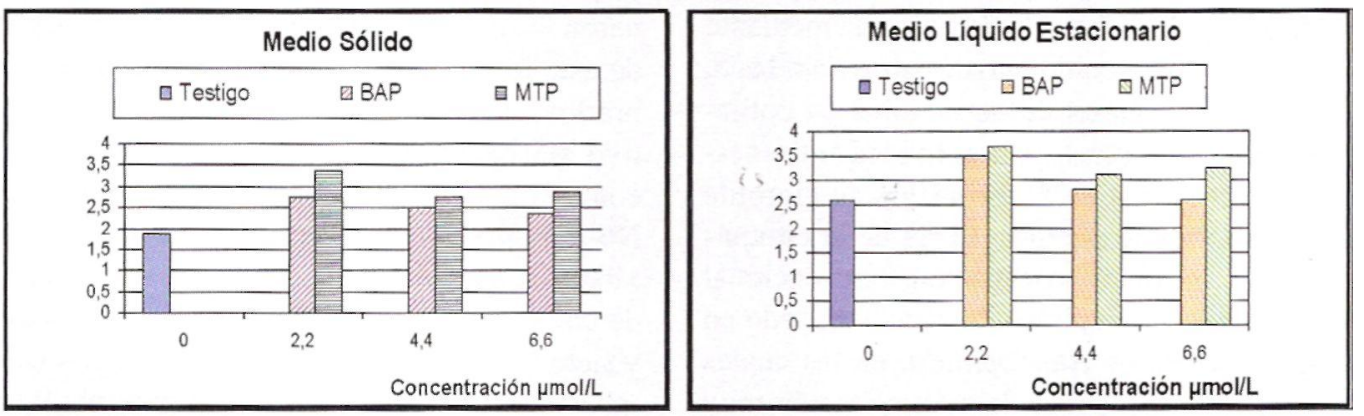

Figura 1. Efecto del BAP y MTP sobre la tasa de multiplicación promedio en $R$. splendens, cultivadas en medio MS sólido y líquido estacionario.

Figure 1. Effect of BAP and MTP on the average multiplication rate of $R$. splendens cultivated in solid and liquid MS-medium.

\footnotetext{
* Financiado mediante Proyecto FIA-BIOT-Ol-A-071
} 